УДК 656.611.1:339.165.4(045)

JEL Classification F 29, F 60, P 45, R 49 DOI 10.31375/2226-1915-2020-1-5-18

Н.Т. Примачев д.э.н., профессор, зав. кафедрой «Экономическая теория и предпринимательство на морском транспорте» prima.nik1@yandex.ru

ORCID: 0000-0003-0192-2894

М.А. Ковылина

к.э.н., доцент кафедрь

«Менеджмент и экономика морского транспорта» kovilinam@gmail.com

ORCID: 0000-0003-2805-9648

Национальный университет «Одесская морская академия», Одесса, Украина

ЗАКОНОМЕРНОСТИ ВЛИЯНИЯ

ГЛОБАЛИЗАЦИОННЫХ ПРОЦЕССОВ

НА ФОРМИРОВАНИЕ ПРОВОЗНОЙ СПОСОБНОСТИ ФЛОТА

Аннотация. Глобализационные процессы формирования параметров рынка морской торговли становятся важнейшей закономерностью, предопределяюшей требования к судовладельческим структурам по критериям адекватности. При этом масштабность формирования международных экономических отношений требует постоянного расширения операторской деятельности судовладельческих структур.

При усилении требований к снижению техногенной нагрузки и повышению безопасности судоходства возрастает единичная стоимость дедвейта, что и ограничивает состав нормальных морских государств. Это условие предопределяет асимметрию распределения фрахтовой выручки по судам различных реестров. Поэтому при выборе стратегии развития начионального флота необходимо ориентироваться не только на достижение транспортной независимости участия в международном разделении труда, но и формирование отрасли, использующей морскую ренту. Международный рынок морской торговли относится к дина мично развивающейся глобальной экономической подсистеме

В основе его состояния лежат определенные закономерности, среди которых выделяется четкая ориентачия на параметры международных экономических отношений, постоянное использова ние инновачионных технологий и иикличность изменения основных показателей.

Тенденция развития морской транспортной индустрии и ее регионализаиии обусловлена сложной совокупностью внешних и внутренних факторов.

Ключевые слова: торговый флот, эффективность, сбалансированность, инновации, сегментация.

() Примачев Н.Т., Ковылина М.А., 2020
УДК 656.611.1:339.165.4(045)

JEL Classification F 29, F 60, P 45, R 49

DOI 10.31375/2226-1915-2020-1-5-18

М.Т. Примачов д.е.н., професор, зав. кафедри «Економічна теорія та підприємництво на морському транспорті»

М.О. Ковиліна к.е.н., доцент кафедри «Менеджмент та економіка морського транспорту»

Національний університет "Одеська морська академія», Одесса, Украӥна

ЗАКОНОМІРНОСТІ ВПЛИВУ

ГЛОБАЛІЗАЦЙНИХ ПРОЦЕСІВ НА ФОРМУВАННЯ ПРОВІЗНОЇ СПРОМОЖНОСТІ ФЛОТУ

Анотація. Глобалізаиійні прочеси формування параметрів ринку морської торгівлі стають важливішою закономірністю, щзо обумовлює завдання розвитку судновласницьких структур за критеріями адекватності. При иьому масштабність формування міжнародних економічних відносин потребує постійного розширення операторської діяльності судноплавних компаній.

При посиленні завдань до зниження техногенного навантаження та підвищення безпеки судноплавства зростає вартість дедвейту, шо обмежує кількість нормальних морських держав. Ця умова обумовлює асиметрію розподілу фрахтової виручки по суднам різних реєстрів. Тому при виборі стратегії розвитку національного флоту необхідно орієнтуватись не тільки на досягнення транспортної незалежності в міжнародному розподілі прачі, але $i$ на ефективне формування галузі, шуо забезпечує використання морської ренти. Міжнародний ринок морської торгівлі відноситься до ринків, які динамічно розвиваються у глобальній економічній підсистемі. В основі його стану лежать певні закономірності, серед яких виділяється чітка орієнтація на параметри міжнародних економічних відносин, постійне використання інновачійних технологій $i$ ииклічність зміни основних показників. Тенденція розвитку морської транспортної індустрії та ї̈ регіоналізаиї обумовлена складною сукупністю зовнішніх $i$ внутрішніх факторів.

Ключові слова: торговельний флот, ефективність, збалансованість, інновації, сегментаиія. 
N. Primachev

DEcon, professor, head of Department of Economic Theory and Entrepreneurship in Maritime Transport prima.nik1@yandex.ru ORCID: 0000-0003-0192-2894

M. Kovylina

CEcon, Associate Professor, Department of Management and Economics of Maritime Transport kovilinam@gmail.com ORCID 0000-0003-2805-9648

National University «Odessa Maritime Academy», Odessa, Ukraine

\section{REGULARITIES OF THE INFLUENCE OF GLOBALIZATION OF PROCESSES FOR FORMATION OF THE FLEETAGE CARRYABILITY}

Abstract. The international maritime trade market belongs to a dynamically developing global economic subsystem. The basis of his condition is a certain set of patterns, among which there is a clear orientation on the parameters of international economic relations, the constant use of innovative technologies and the cyclical nature of changes in key indicators. The development trend of the marine transport industry and its regionalization is due to a complex set of external and internal factors.

All types of merchant shipping, being the most important component of the national and regional transport complex, should be considered as a factor in the general and commercial security of the international division of labor. Therefore, self-sufficient economic systems provide the institutional conditions for technical and technological improvement of the main divisions of merchant shipping. The methods of organizing the work of shipping companies are closely connected with this problem.

The globalization processes of forming the parameters of the maritime trade market are becoming the most important regularity that predetermines the requirements for shipowning structures according to adequacy criteria. At the same time, the scale of the formation of international economic relations requires a constant expansion of the operator activity of shipowning structures. With increasing requirements to reduce the anthropogenic load and increase the safety of shipping, the unit cost of deadweight increases, which limits the composition of normal maritime states. This condition predetermines the asymmetry of the distribution of freight revenue on ships of various registers.

The international maritime trade market belongs to a dynamically developing global economic subsystem. The basis of his condition is certain patterns, among which there is a clear orientation on the parameters of international economic relations, the constant use of innovative technologies and the cyclical nature of changes in key indicators. The development trend of the marine transport industry and its regionalization is due to a complex set of external and internal factors.

Keywords: merchant fleet, efficiency, balance, innovation, segmentation. 
Постановка проблемы. Несмотря на сохранение и даже повышение роли морского транспорта в эффективном участии страны в международном разделении труда, в процессе глобализационных тенденций определенным образом изменяется положение торгового флота отдельных флагов в международной торговле. Усиление положения отдельных национальных экономик в глобальном рыночном пространстве при дифференциации государственной поддержки флота обусловливает повышение приоритета конкурентных преимуществ судоходных компаний. Это предопределило усиление зависимости значительной части тоннажа от текущего состояния фрахтового рынка.

Вследствие этого возникли три проблемы. Первая - расширение роли флота стран Евросоюза и Китая. Вторая - падение роли морского транспорта в оптимизации счета текущих платежей таких стран как Украина. И третья - снижение транспортной безопасности внешней торговли ряда государств и устойчивость оттока валютных ресурсов на оплату фрахта.

Поэтому становится принципиальным исследование условий вхождения новых морских государств в структуру глобального рынка морской торговли.

Обзор последних исследований и публикаций. Морские государства формируют и предопределяют стратегию развития, а, следовательно, и структуру судоходной индустрии [1]. Можно выделить государства, которые подходят комплексно к обеспечению развития морской транспортной индустрии.
Они поддерживают конкурентоспособность подсистем национального морехозяйственного комплекса и стимулируют рост или сохранение провозной способности флота на национальной судостроительной базе. Сюда относятся Япония, Китай и Южная Корея. Традиционно Южная Корея является ведущей судостроительной державой по строительству танкеров, а Япония - по балкерам. Часть их потенциального портфеля заказов с XX1 века аккумулирует Китай.

В Западной Европе строится около $7 \%$ дедвейта, но количество судов достигает $24 \%$ от мирового заказа. Таким образом европейские страны в основном занимаются судоходным бизнесом на уровне экономических интересов и безопасности внешнеторговых отношений. В портфеле заказов судостроительной промышленности Евросоюза выделяются круизные и пассажирские суда $35 \%$, контейнеровозы - $23 \%$ и остальные суда узкой специализации. Таким образом, европейское судостроение удерживает позиции в основном по высокотехнологическому судостроению и в сегменте флота внутреннего водного плавания.

Особую группу государств образуют страны, не обеспечивающие нормализованное развитие морского транспортного потенциала, прежде всего, торгового судоходства. В этом процессе выделяются две причины: тотальное отсутствие капитальных вложений либо недооценка роли фрахтовой независимости участия страны в международном разделении труда. К последним относится Украина. Этим проблемам посвящено 
множество публикаций, среди которых выделяются [2; 3; 4].

Задачи исследования. К основным задачам исследования в условиях непредвиденности влияния отрицательных экстерналий на развитие национального морского транспорта относится формирование принципов минимизации риска нормализованного позиционирования в приоритетных сегментах. В этом отношении важнейшим оказывается управление уровнем средних текущих затрат относительно ожидаемых колебаний фрахтовых ставок. Поэтому, основной задачей становится выбор инвестиционной деятельности по критериям транспортной независимости национального экспорта с учетом приоритетов развития конкурентных компаний. Таким образом, основной задачей исследования является оценка возможностей и рисков устойчивости национального флота.

Основной материал исследования. Современные интеграционные процессы в структуре любого сегмента глобального рынка формируют прямые и эмерджентные результаты. Чаще этот процесс происходит не на уровне национальных государств, а в структуре отдельных регионов. Это же подтверждается и регионализацией транспортно-экономических связей, в основе которых лежит динамика мировой торговли основного фактора развития мореплавания (табл. 1).

Таблища 1

Показатели роста мировой торговли и работы морского транспорта

\begin{tabular}{|l|c|c|c|c|c|c|c|}
\hline Регион и виды & \multicolumn{7}{|c|}{ Годы } \\
\cline { 2 - 8 } морских перевозок & 1997 & 2000 & $2006-2010$ & 2012 & 2016 & 2017 & 2018 \\
\hline Мировая торговля & 9,2 & 7,9 & 5,8 & 2,0 & 1,3 & 4,5 & 2,8 \\
\hline $\begin{array}{l}\text { Индустриальные } \\
\text { страны }\end{array}$ & 10,2 & 7,9 & 4,5 & 0,4 & 1,6 & 3,2 & $2 / 3$ \\
\hline $\begin{array}{l}\text { Развивающиеся } \\
\text { страны }\end{array}$ & 6,6 & 7,9 & 8,1 & 4,5 & 0,9 & 6,0 & 3,5 \\
\hline $\begin{array}{l}\text { Контейнерные } \\
\text { перевозки }\end{array}$ & 10,0 & 9,1 & 7,4 & 3,7 & 2,3 & 6,1 & 2,4 \\
\hline Танкерный сегмент & 7,6 & 7,3 & 6,1 & 1,8 & 5,5 & 1,3 & 1,9 \\
\hline
\end{tabular}

Источник: по данным UNCTAD, 2018

Данные табл. 1 отражают определенную приоритетность влияния индустриально развитых стран на формирование экономического потенциала торгового мореплавания. Эти страны формируют спрос сырьевые ресурсы и на контейнерные технологии, ибо их приоритетом произ- водства является высокотехнологическая продукция, требующая особых условий перевозки. Кроме того, эти страны являются важнейшими потребителями энергоресурсов, что и предопределяет требования к провозной способности и безопасности функционирования танкерного фло- 
та. При этом высокий уровень жизни граждан обусловливается задачи развития круизного флота.

Одновременно динамика основных экономических показателей и производственных результатов функционирования морской транспортной индустрии отражает наличие определенной временной цикличности изменения основных параметров. Определенная сложность удержания позиции по целевым критериям обусловливает поиск особых эффективных менеджерских решений.

Важно при совершенствовании системы транспортного обслуживания экономического развития уточнять характер проявления факторов трансформации транспортно-экономических связей с целью подчинения этому процессу направлений технического и организационного совершенствования деятельности судоходных компаний [5]. Даже в условиях эволюционного изменения в размещении производительных сил как в мировом масштабе, так и в регионе операторской деятельности наблюдаются другие факторы влияния на требования к системе морских перевозок грузов и пассажиров. К ним следует отнести конкуренцию между направлениями, маршрутами и технологиями обслуживания грузопотоков.

Тем не менее, в любом отношении специализированные судоходные компании по разным причинам сохраняют не только использование, но и расширение принципа рефлагирования. Однако важно соблюдение всех требований по обеспечению экономико-правовых условий перевозки и поддержанию общей безопасности судоходства. Открытым регистром по классификации признается тот, кото- рый обладает следующими характеристиками:

- определенным количеством иностранных судов, зарегистрированных в государстве флага;

- возможностью и готовностью государства флага обеспечивать применение на судах минимальных международных социальных норм [3], отражающих стандарты эффективного рынка труда;

- имеется международное досье государства флага, в котором отражена ратификация и реализация конвенций и рекомендаций Международной организации труда.

С учетом отмеченного возрастает роль оптимизации уровня квалификации плавсостава и менеджмента судоходной компании. Именно их действия обеспечивают эффективность использования основного капитала предприятия и оборотного капитала заключенного в грузах, отправителей и получателей. Важно исполнение государством флага параметров охраны труда и окружающей среды относительно международных стандартов.

Отмеченное усложняет задачу достижения необходимой сбалансированности параметров экономического развития по критериям социальной и экологической эффективности. Реализация этого подхода началась с наступлением XX1 века на основе ряда положений [6;7]. Важно соответствие политике ООН и Евросоюза относительно эффективности функциональной и инвестиционной деятельности транспорта. При этом кроме чисто коммерческих задач повышается критериальная роль экологических ограничений и соблюдения социальных стандартов. 
DEVELOPMENT OF MANAGEMENT AND ENTREPRENEURSHIP METHODS ON TRANSPORT, № 1 (70), 2020
РОЗВИТОК МЕТОДІВ

УПРАВЛІННЯ ТА ГОСПОДАРЮВАННЯ

НА ТРАНСПОРТІ, № 1 (70), 2020
Так, по программе Евросоюза выделяются средства на реализацию альтернативных проектов, обеспечивающих расширение региона специальных технологий (морских дорог). Кроме того, внимание сконцентрировано на направлении средства на строительство дорог и других объектов инфраструктурного комплекса. При этом следует отметить, что специальные технологии в транспортном обслуживании отдельных грузопотоков нельзя отнести к массовым. И только это существенно ограничивает решение транспортных задач по программе Ассоциации Украины и Евросоюза.

Сохраняется приоритет устойчивого расширения своих позиций известными брендами европейского транспортного обслуживания. В част-ности, «Гамбургский порт и логис-тическое акционерное общество» (HAALA) реализует принцип приоритетного позиционирования. Он владеет и управляет контейнерными терминалами и железнодорожными линями, обслуживающими грузопотоки Средней Европы. Компания стремится развивать отношения и с украинскими транспортниками. Однако ведомственность управления железной дорогой в Украине и фактическое неиспользование транспортного потенциала Днепра сужает сотрудничество компании на уровне Одесского порта.

Экономический кризис 2009 года особо жестко отразился на экономике Украины и на переработке контейнерных грузов в национальных портах. Одесский порт потерял $60 \%$ грузооборота, в Гамбурге же падение контейнерооборота составило только $30 \%$. Последующее приращение объ- ема транспортных работ подчеркнуло дифференциацию отношений к морскому транспорту в развитых странах и в Украине.

С целью оптимизации грузовых потоков еще в 1980-е годы Еврокомиссия сформировала принцип транспортных коридоров [5]. Затем сделана попытка к этому процессу подключить транспортную систему Восточной Европы для обеспечения транспортно-экономических связей с Юго-Восточной Азией. Главной задачей рассматривалась разгрузка Западной Европы от автотранспорта и формирование новой парадигмы конкурентного обслуживания внешнеторговых и региональных грузопотоков.

Автотранспорт в предкризисном периоде обеспечивал $44 \%$ объемов перевозок в странах ЕС, морской -41 , железнодорожный -8 и внутренний водный $-4 \%$. В Украине это соотношение существенно отличается. Недопустимо низкая доля использования морского и речного транспорта.

Среди факторов сбалансированности функциональной деятельности специализированных судоходных компаний следует выделить их конкурентоспособную доступность к открытым сегментам фрахтового рынка и равноправие взаимоотношений. К сожалению, из-за игнорирования принципа транспортной независимости Украина не способна реализовать стандартные технологии и организацию костерного судоходства. Поэтому приоритеты и денежные потоки уходят к иностранным судовладельцам. Достаточно рассмотреть открытие турецким оператором Medtrans нового ро-ро сервиса на Черном море. 
Усиливается в управлении хозяйственной деятельностью морской транспортной индустрии принцип альтернативного с позиции приоритетов использования средств. Именно нарушение этого правила в отношении портовых сборов в Украинских портах на основе финансирования содержания АМПУ и обусловливает усиление разрыва между национальными и конкурирующими портами.

На рис. 1 представлена совокупность целей и их последовательность в реализации основной функциональной и экономической за- дачи судовладельческих предприятий страны на основе сбалансированности параметров, предопределяющих системную устойчивость. Принципиальным рассматривается подход к достижению соответствия провозной способности флота относительно макроэкономических параметров национальной экономики. Главным следует рассматривать отношение судовладельцев к изменению позиции по критериям инвестиционной эффективности и принимать стимулирующее воздействие с учетом общегосударственных интересов.

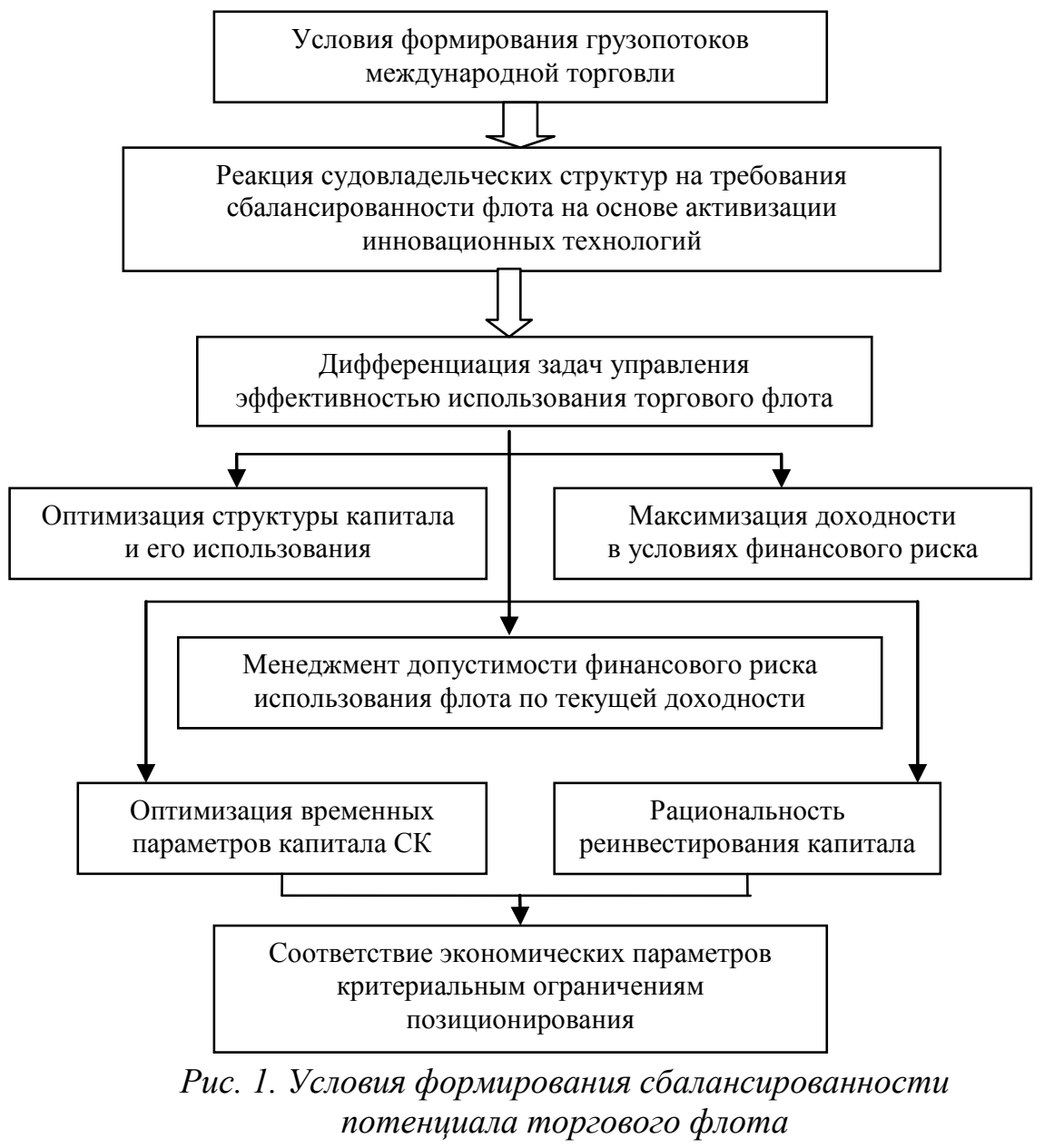

Источник: разработано авторами 
DEVELOPMENT OF MANAGEMENT AND ENTREPRENEURSHIP METHODS ON TRANSPORT, № 1 (70), 2020
РОЗВИТОК МЕТОДІВ

УПРАВЛІННЯ ТА ГОСПОДАРЮВАННЯ

НА ТРАНСПОРТІ, № 1 (70), 2020
Развитие специализированного судоходства на основе многообразия инновационных и менеджерских технологий подтверждают эксперименты, основанные на выборе направлений роста отдачи ресурсов в условиях конкуренции идей.

Данные рис. 1 раскрывают принципиальные задачи и направления формирования локальных морских транспортных комплексов при одновременном использовании интеграционных технологий функциональной деятельности торгового флота. В сложившемся усилении роли международного разделения труда сохраняет свою значимость главная цель формирования конкурентного потенциала СК - обеспечение эффективности обслуживания грузопотоков на основе достижения финансовой независимости предприятия.

Тем не менее, в реальных условиях функционирования рынка морской торговли вследствие внешнего влияния возможны существенные отклонения от стандартных судовладельческих целей при реализации инвестиционной и функциональной деятельности. Особое место занимает процесс управления нормализацией состояния владельцев капитальных ресурсов судоходных компаний. Различие форм собственности должно обеспечивать конкурентные условия формирования провозной способности по критериям возмещения инвестиционных ресурсов за расчетный период жизненного цикла проекта.

При этом следует учитывать не только отраслевые особенности формирования цикличности функциональной деятельности отдельных подсистем морской транспортной индустрии. На ее характер оказывает влияние и сегмент операторской деятельности. Так при обслуживании грузопотоков с высокоценной продукцией мировой торговли размах падения спроса оказывается более значительным по сравнению с грузопотоками продукции кратковременного жизненного цикла.

Вместе с тем наличие сложной совокупности целей главным остается формирование фирменной стратегии устойчивого позиционирования, характеризующегося минимальным уровнем риска оказаться в состоянии финансовой нестабильности. Поэтому принципиальным в управлении развитием и функциональной деятельностью является ориентация как на предпринимательские, так и на институциональные условия выбора системы инвестирования и оценки целесообразного времени реинвестирования. При этом подходе принципиальным становится выбор времени выхода на вторичный рынок торго-вого флота или рынка скрепинга.

В структуре рынка морской торговли при любой форме организации [8] среди различных компаний и внутри отдельных морских ренджей развита демонстрация приоритета, в основе которого выделяется позиция качественных характеристик перевозочного процесса.

В этом аспекте следует рассматривать возможности расширения конкурентного участия в перевозках грузов государств, не имеющих выхода к открытому морю. Так более 15 миллионов т грузов белорусской внешней торговли перевозится морским путем. В этой стратегии рационализация использования морских портов, судов смешанного плавания может существенно повысить эффек- 
тивность транспортировки с позиции интересов резидентов Беларуси.

При сопоставлении стоимости доставки этой группы грузов предпочтение отдается портам Клайпеда, Вентспилс и Николаев. Российские порты по стоимости оказываются неконкурентоспособны. Главным становится выбор в системе управления грузопотоками, наряду со стоимостными характеристиками, надежность и устойчивость позиционирования маршрута внешних транспортно-экономических связей.

Для портов Украины проблемой остается приоритет арендных отношений, основанных на выделении территории под проекты инвесторов. С позиции государства - владельца акватории и территории риск заключается в оттоке прибыли за период жизненного цикла реализованного инвестиционного проекта [9].

Это обусловлено не только массовостью грузопотоков, но и непредвиденностью колебания тарифных ставок (рис. 2). При этом краткосрочные колебания (внутри отдельных кварталов) существенно усложняют финансовое состояние отдельных, особенно малотоннажных судоходных компаний.

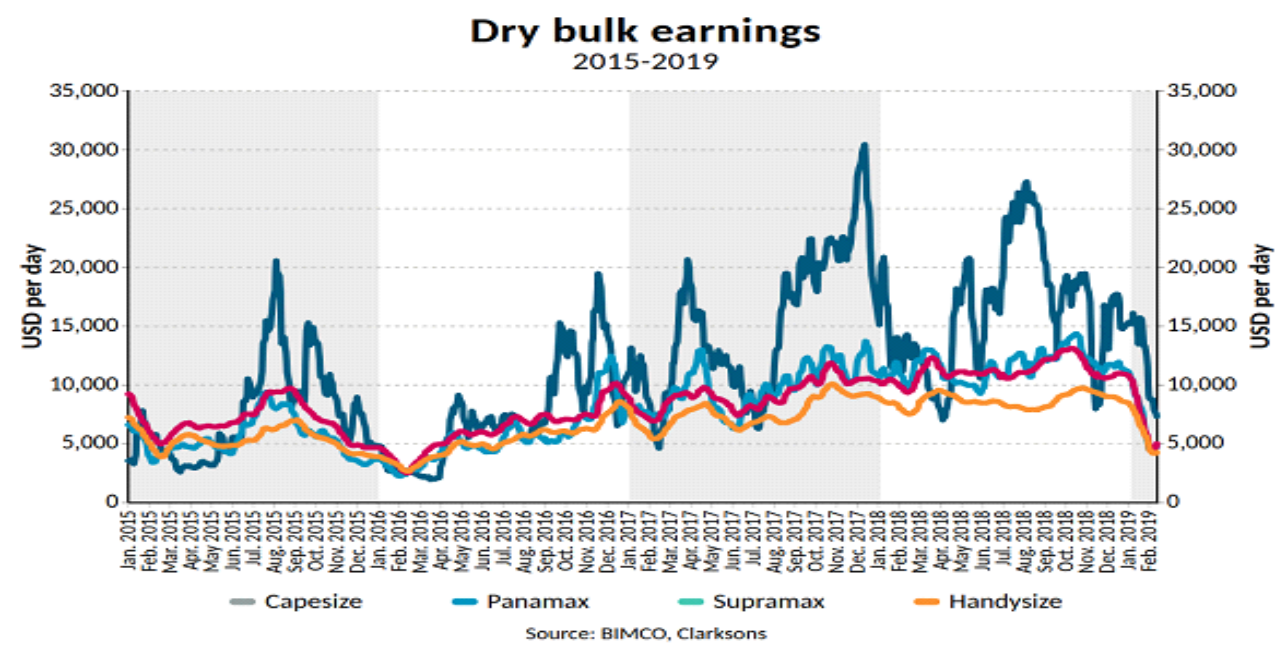

Рис. 2. Характер изменения тайм-чартерных ставок балкерного сегмента по условиям активности фрахтового рынка

Источник: по данным ВIMCO, Clarksons

Как видно из динамики ценовых характеристик одного из определяющих глобальный рынок морской торговли сегментов (рис. 2), важнейшим параметром ценовой устойчивости различных тоннажных групп балкерного флота является показатель экономического роста. Усиление предложения без сбалансированного спроса в глобальной экономике и предопределяет падение макроэкономических показателей. Этот процесс усугубляется в системе морской транспортной индустрии, предвари- 
тельно настроенной на сбалансированность спроса и предложения в расчетном временном периоде.

При этом следует учитывать, что в значительном количестве случаев грузопоток, который формируется в базовых портах регионов операторской деятельности, не характеризует производство и спрос в данной стране. Поэтому необходимо внимание сосредоточить на регионах транспортного обслуживания и на технологии и организации транзитных грузопотоков. С этим связаны проблемы позиционирования по критериям превосходства технического обслуживания флота [10] различных стран.

В этом аспекте достаточно обратить внимание на развитие торгового флота Германии, являющейся основным звеном Евросоюза. В стране насчитывается порядка 450 различных судоходных компаний. С концентрированным капиталом и значительной провозной способностью имеется 10 компаний. Около 90 относятся к средним морским транспортным предприятиям. Значительное число - более 250 судоходных компаний образуют группу специализированных. Многие из этих компаний имеют по одному судну, характеризующихся финансовой неустойчивостью из-за ограниченности техникоэкономического уровня технологии обслуживания грузопотоков.

Морской транспорт этой страны концентрирует формирование стратегии по правилам устойчивости в глобальном транспортном пространстве и отражает общие закономерности рынка морской торговли.

Выводы. В любом случае определяющее значение для выбран- ного сегмента позиционирования морского транспорта имеет характеристика инновационных технологий. Они в основном обусловливают структуризацию флота и направления развития портов. Например, рост контейнерооборота за период 2000-2019 годов в TEU основывался в основном на инновационных направлениях развития не только флота.

В XXI веке изменяются темпы нарастания перевозок в основных сегментах глобального рынка морской торговли. Это предопределяет и позиции судостроительных заводов. По контейнерной технологии перевозится более половины всех генеральных грузов. Усиливается контейнеризация других групп грузов, что необходимо учитывать при восприятии текущего состояния грузопотока в других сегментах рынка морской торговли.

Для украинского транзитного пространства необходимо учитывать, что на европейский транспортный сектор приходится 22-23 процентов мирового оборота контейнерных грузов. Однако этот грузопоток базовых портов требует расширения технологии трансшипмента, развитие которого предполагает использование судов смешанного плавания. При этом достаточно учитывать то, что постоянно возрастает приоритет китайского сегмента в формировании грузопотоков мировой торговли.

Рыночные принципы ценообразования в системе торгового судоходства отражают состояние текущей сбалансированности судопотока и грузопотока. Тем не менее, не достигается необходимого выравнивания спроса и предложения по альтернативным вариантам качественных 
показателей. C позиции грузовладельцев формируется маржинальная оценка преимуществ альтернативных транспортных маршрутов, предопределяющих возникновение синергии. Поэтому возникают задачи институционального регулирования и реализации специальных форм поддержки социально и экологически значимых проектов.

Тем не менее, в любых условиях сохраняются приоритеты регионального развития базовых подразделений производственной инфраструктуры. Потребность в развитии транспортного судоходства обусловливается жестким проявлением факторов, отражающих прежде всего, характер участия национальной экономики в международном разделении труда. Однако, инновационные направления развития торгового судоходства усиленно регулируются снижением интенсивности экологической нагрузки на инвестиционные программы судовладельцев. Это одновременно сказывается и на оптимизации направлений реализации транспортно-экономических связей.

Как показывает практика и реальность функционирования локальных сегментов фрахтового рынка, затраченные усилия на создание отдельных математических моделей оказались не плодотворными. Это объясняется наличием сложной совокупности факторов формирования грузопотоков и провозной способности специализированного флота. Они отличаются сложной изменчивостью и фактически не поддаются практической формализации.

Особенностью работы судоходных компаний в структуре традиционных транспортно-экономических связей является относительная стабильность грузопотоков, в основе которых лежит размещение производительных сил. Для других морских ренджей характерно существенно различие темпов роста объема перевозок и выполненной транспортной работы [1]. В основе этой тенденции лежит дифференциация не только темпов развития отдельных экономических подсистем (Китая, Бразилии), но и условие освоения отдаленных месторождений углеводородов и сырьевых ресурсов.

В этих условиях обращает на себя действие Еврокомиссии в отношении выработки политики последовательного развития и поддержки портов на основе индивидуальных характеристик. Главными направлениями выбрано совершенствование использование экономического потенциала по критериям обеспечения социальных и экономическим потребностей сообщества. При этом выделяются приоритеты безопасности и защиты окружающей среды [6].

Тем не менее, в основе позиционирования флота специализированных компаний лежат противоречивые факторы. Среди них выделяется транспортная политика экономического союза или отдельных государств, коммерческие и экологические преимущества морского транспорта. В то же время принципиальное значение занимает конкуренция между перевозчиками на основе дифференциации функциональных преимуществ.

Поэтому основополагающее значение приобретает экономичность обслуживания грузопотоков и надежность работы маршрута. В этом плане управление техническим состоянием 
и организацией работы судоходных компаний сводится к выбору инновационных проектов [11] развития.

Следовательно, основным аспектом становится совершенствованием методов управления эффективностью работы флота по критериям предпринимательской и внесистемной эффективности.
Независимо от степени интеграции экономических систем и концентрации производства по приоритетам минимизации капитальных или трудовых затрат, сохраняется роль ресурсных сырьевых потоков, требующих использования стратегии лидерства по затратам.

\section{СПИСОК ЛІТЕРАТУРИ}

1. Review of Maritime Transport. Report by the UNCTAD - New York and Geneve: $U N, 2018.167 p$.

2. Жихарева В.В. Теория и практика инвестиционной деятельности судоходных копаний. Одесса: ИПРиЭЭИ, 2010. 480 c.

3. Котлубай О.М. Економічні механізми розвитку торговельного мореплавання в Україні. Одеса: ІПРта ЕЕД, 2004. 454 c.

4. Сенько О.В. Організачійно-економічний механізм параметричного управління морською транспортною індустрією. Чернігів: ЧНТУ, 2019. 359 с.

5. Примачев Н.Т., Примачева Н.Н., Пархоменко И. Н. Управление экономической деятельностью судоходных компаний. Одесса: НУ «ОМА», 2016. $346 c$.

6. Повестка дня на XX1 век/Конвенция ООН. 1993, 300 c. URL: https// www. un.org >documents >decl>convention >agenda 21

7. Branch A. E Distionary of Shipping International Business Trade Terms and Abbreviations. London: WITHERBY, 1999. 953 p.

8. The Handbook of Maritime Economics and Business / It is edited by Prof. Costas Grammenos. - City University Cass Business School, London: Lloyd's of London Press, 2002. 930 p.

9. Моряков К. Проект для развития морской отрасли // Порты Украины, № 1 (173), 2018. C. 32-35.

10. Кругман П.Р., Обстфельд М. Международная экономика. СПб.: Питер, 2003. $832 c$.

11. Аткиссон А. Как устойчивое развитие может изменить мир. М.: БИНОМ, 2011. $455 \mathrm{c}$.

12. Kroslakova, M., Kubickova, V., Jurkovičová, L., Kubiniy, N. Dynamics of high growth enterprises-«gazelles»-in Czech Republic // Problems and Perspectives in Management 13(2):27-35, 2015. URL: https://www. researchgate. net/ publication/282679988_Dynamics_of_high_growth_enterprises-gazelles-in_ Czech_Republic

13. Kotowska I., Mańkowska M., Pluciński M. Inland Shipping to Serve the Hinterland: The Challenge for Seaport Authorities // Sustainability 10(10):3468, 2018 URL:https://www.mdpi.com/2071-1050/10/10/3468 
14. Oneshko S., Ilchenko S. Financial monitoring of the port industry companies on the basis of risk-oriented approach // Investment management and financial innovations. 2017. Vol. 14, № 1(contin.). C. 181-190.

\section{REFERENCES}

1. Review of Maritime Transport. Report by the UNCTAD - New York and Geneve: UN, 2018. $167 p$.

2. Zhikhareva, V. V. (2010). Teoriya i praktika investitsionnoy deyatel'nosti sudokhodnykh kopaniy [Theory and practice of investment activities of shipping companies.]. Odessa: IPRiEEI, 480 [in Russian].

3. Kotlubay, O. M. (2004). Ekonomichni mekhanizmy rozvytku torhivel'noho moreplavannya $v$ Ukrayini [Economic mechanisms for the development of commercial navigation in Ukraine]. Odesa: IPRta EED, 454 [in Ukrainian].

4. Senko, O.V. (2019). Orhanizatsiyno-ekonomichnyy mekhanizm parametrychnoho upravlinnya mors'koyu transportnoyu industriyeyu [Organizational and economic mechanism of parametric management of the maritime transport industry]. Chernihiv: CHNTU, 359 [in Ukrainian].

5. Prymachev, N. T., Prymacheva, N. N. \& Parkhomenko, Y. N. (2016). Upravlenye ékonomycheskoy deyatel'nost'yu sudokhodnykh kompanyy [Management of Shipping Companies Economic]. Odessa: NU «OMA», 346 [in Russian].

6. Povestka dnya na KHKH1 vek/Konventsyya OON. 1993, 300. Retrieved from https//www.un.org >documents >decl > convention >agenda 21

7. Branch, A. E. (1999). Distionary of Shipping International Business Trade Terms and Abbreviations. London: WITHERBY, 953.

8. The Handbook of Maritime Economics and Business (2002). It is edited by Prof. Costas Grammenos. - City University Cass Business School, London: Lloyd's of London Press, 930.

9. Moryakov, K. (2018). Proyekt dlya razvitiya morskoy otrasli [Project for the development of the marine industry]. Porty Ukrainy - Ukrainian ports, № 1 (173), 32-35 [in Russian]

10. Krugman, P. R. \& Obstfel'd M. (2003). Mezhdunarodnaya ekonomika [International economics]. SPb.: Piter, 832 [in Russian].

11. Atkisson A. (2011). Kak ustoychivoye razvitiye mozhet izmenit' mir [How sustainable development can change the world]. M.: BINOM, 455 [in Russian].

12. Kroslakova, M., Kubickova, V., Jurkovičová, L. \& Kubiniy, N. (2015). Dynamics of high growth enterprises-«gazelles»-in Czech Republic // Problems and Perspectives in Management 13(2):27-35. Retrieved from https://www.researchgate.net/publication/282679988_Dynamics_of_high_growth_enterprises-gazelles-in_Czech_Republic

13. Kotowska I., Mańkowska M. \& Pluciński M. Inland Shipping to Serve the Hinterland: The Challenge for Seaport Authorities // Sustainability 10(10):3468, 2018 URL:https://www.mdpi.com/2071-1050/10/10/3468 
14. Oneshko S. \& Ilchenko S. (2017). Financial monitoring of the port industry companies on the basis of risk-oriented approach. Investment management and financial innovations. Vol. 14, № 1(contin.), 181-190.

Стаття надійшла до редакиії 24.02.2020

Посилання на статтю: Примачев Н.Т., Ковылина М.А. Закономерности влияния глобализационных процессов на формирование провозной способности флота // Розвиток методів управління та господарювання на транспорті: Зб. наук. праць, 2020. № 1 (70). С. 5-18. DOI 10.31375/2226-1915-2020-1-5-18.

Article received 24.02.2020

Reference a JournalArtic: Primachev, N. \& Kovylina, M. (2020). Regularities of the influence of globalization of processes for formation of the fleetage carryability. Development of management and entrepreneurship methods on transport, 1 (70), 5-18. DOI 10.31375/2226-1915-2020-1-5-18. 